\title{
Encerramiento y apertura: Pascual Duarte y su texto
}

JOHN W. KRONIK

Cornell University

El calabozo, la cárcel $\mathrm{u}$ otros espacios clausurantes constituyen una imagen lo bastante arraigada en la tradición literaria para haber adquirido ya una dimensión mítica. Si es dudoso que la tuviera en alguna ocasión, modernamente el espacio narrativo o dramático ha perdido toda su inocencia. Tanto el escritor como el lector reconocen que la construcción espacial, más que un elemento accesorio donde se colocan los personajes y la acción, posee en sí un valor comunicativo y codificador. En la literatura de este siglo, las estructuras aprisionantes se manifiestan como una constante de vastas dimensiones porque para el escritor, sea novelista o dramaturgo, el espacio encerrado es la proyección metafórica por excelencia de la circunstancia social y existencial del ser humano que lo ocupa.

La celda donde está encarcelado Pascual Duarte y donde escribe sus memorias es el componente clave del sistema significante en la primera novela de Camilo José Cela. El espacio celular es la única realidad de La familia de Pascual Duarte y de su protagonista: el presente narrativo del relato en primera persona. En esta celda pasa Pascual su vida novelesca y reconstruye su vida histórica. Y en esta celda queda definido su futuro: su futuro de hombre y de personaje literario.

El encarcelamiento y la condena de Pascual, no por el asesinato 
de su madre sino por otro crimen en contra de la sociedad, separan al individuo de aquella sociedad. Se establece una diferencia y una barrera entre fuera y dentro. Encontrarse dentro de una celda equivale a encontrarse fuera de la sociedad. Siendo prisionero, Pascual no está libre. ¿Se puede suponer entonces que está libre el que se sitúa dentro de la sociedad? No, porque la fórmula no es aplicable al revés. Cada espacio encerrado supone la existencia de un espacio exterior, una apertura, pero la sociedad no es la solución liberadora desde la perspectiva de este prisionero. La sociedad es sencillamente otra forma de encarcelación. En una ocasión anterior, después del castigo por la muerte del Estirao, Pascual se comporta bien y le ponen en libertad. He aquí su comentario:

y me soltaron; me abrieron las puertas, me dejaron indefenso ante todo lo malo. Me dijeron:

-Has cumplido Pascual; vuelve a la lucha, vuelve a la vida, vuelve a aguantar a todos, a hablar con todos, a rozarte otra vez con todos...

Y creyendo que me hacían un favor, me hundieron para siempre.

(p. 170 $)^{1}$

Es lógico que la conciencia de la libertad siempre acompañe al prisionero. Desde su celda, Pascual puede ver el campo y la carretera de Portugal; puede ver a una familia que cruza libremente por un sendero. El preso, según cuenta Pascual, imagina el campo verde y lozano, fértil y hermoso, y a los campesinos trabajando con alegría bajo el sol. Esta visión de un paisaje ideal vislumbrado desde la celda es un motivo predilecto de los románticos ${ }^{2}$. La realidad que descubre Pascual es otrả: «Cuando salí encontré al campo más triste, mucho más triste, de lo que me había figurado [...] yermo y agostado como los cementerios, deshabitado y solo" (p. 171). El mismo desengaño le espera cuando vuelve a su terruño, donde la realidad también es muy distinta de la ilusión de «mi pueblo, mi casa, mi familia, mi madre, $m i$ santa hermana" que se había labrado (pp. 171-72; el subrayado es mío). Es irónico que desde la perspectiva del último encarcelamiento -el que genera el recuerdo de este encerramiento por el asesinato del

1. Las citas se refieren a la edición que el autor considera la definitiva: Camilo José Cela, Obra completa, I, Barcelona, Destino, 1962.

2. Véase libro imprescindible de Victor Brombert, La Prison romantique, París, José Corti, 1975; las citas se refieren a la traducción inglesa, The Romantic Prison, Princeton, Princeton University Press, 1978. Consultar también Michel Foucault, Discipline and Punish: The Birth of the Prison, trad. Alan Sheridan, New York, Vintage Books, 1979. 
Estirao- el primer secuestro aparezca como un momento positivo. Aunque "preso y cautivo», retrospectivamente Pascual en su estado de prisionero se ve "libre de toda culpa", "libre de nuevos delitos de sangre» (pp. 169-70). La suspensión del castigo le hundió en castigos aún peores.

Tristes son las alternativas que se ofrecen al individuo: el encarcelamiento particular - la celda- o el encarcelamiento comunal -la sociedad $^{3}$-. Si en determinados momentos le parece preferible la celda, no sorprende el impulso de escaparse de su circunstancia social. Después de la muerte de su hijo y las acusaciones de las mujeres, Pascual huye de su casa. Lo hace en secreto y de noche, como si se escabullera de una cárcel, huyendo por huir, campo adelante. El tren le aleja aún más, hacia Madrid. Allí no lo pasa mal, pero en su primer contacto con la libertad, la ciudad se convierte én una amenaza para Pascual. Le asusta la incertidumbre con la que de súbito tiene que enfrentarse; le asusta también la noche madrileña llena de truhanes y rateros. El frío y la humedad le hacen sufrir; la gente le parece rara y sus costumbres le tienen asombrado. Por fin, el instinto de huida le hace reanudar la marcha hacia terrenos más lejanos. El puerto de mar, con su horizonte infinito y el misterio de lo desconocido, es un motivo tradicional de escape. Por esta tentación de un mundo prometedor más allá del suyo se ve atraído Pascual a La Coruña. Pero ingenuo y sin los fondos necesarios, Pascual fracasa, y en vez de experimentar la apertura deseada, termina por incorporarse a la capa más baja del puerto, trabajando en un burdel. El suyo ha sido un viaje mítico al revés, propio de un antihéroe. "La choza sobre la carretera" y lo que en ella había dejado empiezan a atraerle de nuevo, y a la tentativa liberadora que se había iniciado con tanta esperanza le da remate Pascual con estas palabras: «mi huida, mi mayor pecado, el que nunca debí cometer y el que Dios quiso castigar quién sabe si hasta con crueldad...» (p. 155). El escape de su circunstancia, que no le había proporcionado mejoramiento alguno, termina por ser un vacío de dos años encerrado por la miseria y adversidades inalterables, un sólo capítulo de la novela (cap. $\left.{ }^{\circ} 14\right)$ rodeado del texto implacable.

Pascual Duarte siempre vuelve a los espacios que le encierran: a

3. En la dimensión social de esta novela han insistido, entre otros, J.S. Bernstein, «Pascual Duarte and Orestes", Symposium, XXII, 1968, pp. 301-318; y Gonzalo Sobejano, "Reflexiones sobre "La familia de Pascual Duarte"", Papeles de Son Armadans, 48, 1968, pp. 19-58, y también en su Novela española de nuestro tiempo, 2. ${ }^{\mathrm{a}}$ ed., Madrid, Prensa Española, 1975, pp. 89-105. 
su casa, a su familia, a la cárcel. Su enclaustramiento parece inevitable, pues ninguna alternativa que escoge le lleva a una solución; al contrario, con cada paso se enmaraña más en su dilema existencial. Prisionero del mundo en el cual ha sido condenado a vivir, este cordero pascual se siente víctima de una "mala estrella" o de "algún mal aire traidor". Aunque no sea más que por su situación particular y tal vez por una racionalización equivocada, le abruma la sensación de un destino contrario. Con su mirada retrospectiva, se pinta a sí mismo como un predestinado, un preso por nacimiento ${ }^{4}$. Por eso dice de su madre: «Con echarme al mundo no me hizo ningún favor, absolutamente ninguno..." (p. 192), y al asesinarla la castiga por haberle parido. La imagen de un espacio asfixiante que emplea Pascual para pintar su indecisión al encontrarse paralizado ante el lecho de su madre, es una metáfora que también sirve para proyectar la realidad de su vida (y además, de su muerte): "Estaba metido como en un lodazal donde me fuese hundiendo, poco a poco, sin remedio posible. El barro me llegaba ya hasta el cuello. Iba a morir ahogado como un gato...» (p. 193).

En su condición de hombre encerrado, Pascual no es un caso aislado. Tiene algo en común con ese contemporáneo suyo en L'Étranger de Camus, Meursault, quien pasa sus últimos días en una celda que señala su separación del mundo y de sí mismo ${ }^{5}$. También es heredero de la tradición de Kafka, cuyos espacios amenazan, transforman y ahogan al individuo. Para el hombre mortal, sugiere Cela, no hay escape de su circunstancia cerrada, idea que comparte con Sartre, quien más que nadie ha hablado a través de recintos emparejados que atrapan a sus personajes en la náusea, por ejemplo en su cuento significativamente titulado La Chambre y en su drama bien conocido, Huis-clos. Tiene razón David Foster cuando escribe: «It is certainly the psychology of the man trapped by life that is uppermost in Cela's mind, not the mere anatomy of his behavior as that man describes it". $Y$ dice Paul Ilie: «El deseo de escapar de Pascual es el ansia de un yo racional abstracto por verse libre de su prisión existencial» ${ }^{6}$.

4. Cuando durante su luna de miel en Mérida un grupo de chicos se mofan de Lola y Pascual, éste pregunta: ¿Qué maligna crueldad despertará en los niños el olor de los presos?» (p. 112).

5. Cf. Jorge A. Marbán, Camus y Cela. El drama del antihéroe trágico. Barcelona, Picazo, 1973.

6. David W. Foster, Forms of the Novel in the Work of Camilo José Cela. Columbia, University of Missouri Press, 1967, p. 21; Paul Ilie, La novelistica de Camilo José Cela, Madrid, Gredos, 1963, p. 76. 
Como veremos más adelante, las memorias que nacen del secuestro apuntan hacia un desdoblamiento introspectivo por parte del individuo. El yo que existe se separa del yo que ha existido ${ }^{7}$. La retirada solipsista puede ser voluntaria, como lo es en Proust y en la mayor parte de los herederos angustiados del hombre subterráneo de Dostoievski, o puede ser impuesta, como en el caso de Pascual. Pero trátese de un exilio o de un autoexilio, el resultado es una dolorosa enajenación personal por encima de la social.

La celda no es la única metáfora de encerramiento en La familia de Pascual Duarte, aunque es la principal. A pesar de que según el título la familia parece ser posesión de Pascual, la verdad es que en la sucesión de signos lingüísticos que ofrece el título, la palabra dominante es "familia". Protagonista y materia de su historia, Pascual sin embargo es prisionero de su circunstancia familiar. Siempre vive bajo la sombra inescapable de su madre y aplastado por su condición de hijo, hermano, esposo y padre. Mientras que la novela en su título evoca a toda la familia, el paquete de folios que contiene el manuscrito lleva sencillamente la inscripción «Pascual Duarte». El texto doble presenta a Pascual Duarte confinado dentro de la familia de Pascual Duarte.

La casa de Pascual, "estrecha y de un solo piso" (p. 59), armoniza en su vulgaridad con la posición social de los que la ocupan. El lector no puede menos de apreciarla como una estructura que forma y deforma a Pascual. Cuando al final de su relato se lanza corriendo al campo, las últimas palabras que escribe son: "Podía respirar...». No hay que perder de vista el hecho de que la casucha está situada fuera del pueblo, tal como Pascual se encuentra al margen de la sociedad, a diferencia de su última víctima, el Conde don Jesús, cuya vivienda elegante adorna la plaza central. Del mismo modo, la región de Extremadura con referencia a España entonces era tan marginal como la casa de Pascual. En efecto, el encierro y la marginación son sentimientos que se juntan para acompañar a Pascual. Frente a su am-

7. Robert C. Spires, La novela española de posguerra, Madrid, Cupsa, 1978, pp. 32, 40, subraya esta doble existencia temporal de que disfruta Pascual. La había señalado antes Mary A. Beck, "Nuevo encuentro con "La familia de Pascual Duarte"», Revista Hispánica Moderna, XXX, 1964, p. 288. Michael D. Thomas desarrolla en términos morales y psicológicos la escisión entre Pascual-protagonista y Pascual-narrador en "Narrative Tension and Structural Unity in Cela's La familia de Pascual Duarte», Symposium, XXXI, 1977, pp. 165-178. 
biente inmediato y al mundo general, Pascual se siente al mismo tiempo atrapado y enajenado. Lo que dice de su mujer, su madre y su hermana viene al caso: "Tres mujeres hubieron de rodearme [...]; tres mujeres a las que por algún vínculo estaba unido, aunque a veces me encontrase tan extraño a ellas como al primer desconocido que pasase, tan desligado de ellas como del resto del mundo" (p. 131). La indiferencia con que el jefe de la estación de su pueblo recibe a Pascual, de vuelta del presidio, simboliza el abismo que existe entre Pascual y su "familia», entre el hombre y su prójimo. Por eso se define a sí mismo Pascual como «este desgraciado derrotado que tan poca compasión en usted y en la sociedad es capaz de provocar" (p. 170).

Pero si Pascual queda alienado incluso de su grupo social más inmediato, también forma parte del pueblo lo suficientemente para perderse en su insignificancia y marginalidad. "En el vacío de la casa, del pueblo y de la patria Pascual Duarte existe en soledad, con su sombra por única compañera", escribe Sobejano (PSA, p. 33). Este pueblo es la unidad más reducida de una cadena de sectores geográficos cada vez más amplificados. Torremejía-Almendralejo-BadajozExtremadura: son como una serie de cajas japonesas; sólo que aquí son españolas, porque a fin de cuentas España es la última entidad en esta sucesión siempre más amplia de localizaciones circunscritas: España, aislada y también marginada del mundo en su condición miserable.

Pasando por la novela, el lector ve multiplicarse los espacios cerrados. El padre de Pascual, a quien también habian mandado a presidio por contrabandista, muere de rabia encerrado en una alacena. Su hermana Rosario nace a la miseria y empieza su vida de modo sofocante: «le armaron un tingladillo con un cajón no muy hondo, [...] envuelta en tiras de algodón y tan tapada que muchas veces me daba por pensar que acabarían por ahogarla" (p. 73). El hermano de Pascual, Mario, muere ahogado en una tinaja de aceite con la nariz pegada al barro del fondo. Pascual no está exagerando cuando escribe: "La verdad es que la vida en mi familia poco tenía de placentera" ( $p$. $69)$.

Los espacios que asfixian a los personajes dentro de la novela encuentran un eco en la estructuración del texto. Las memorias de Pascual consisten en diecinueve secciones, de las cuales las secciones seis y trece tienen lugar en el presente en la celda de Pascual, mientras que las otras son historia retrospectiva. De este modo, cada 
una de las tres partes de su confesión representa la ficción del pasado enjaulada en la realidad presente. Paralelamente, las dos escenas en la cárcel están por su parte encajonadas en el texto que las rodea. Así queda indicado gráficamente que Pascual es prisionero de su pasado y que su pasado está circunscrito por su presente en la cárcel ${ }^{8}$.

Por lo que toca a la técnica, es aún más digno de atención el que las confesiones de Pascual están enmarcadas por las notas de un supuesto transcriptor y por otros textos con que se abre y se clausura la novela. En un artículo fundamental escribe Dru Dougherty: «La novela de Pascual Duarte estriba en su rico ensamblaje formal, que deja entrever un relato interno incompleto. [...] es una sucesión de textos escritos por distintos personajes sobre una vida humana truncada a destiempo [...]. Para llegar a la novela hay que sumar todos los textos y prestar oído a todas las voces que hablan de ellos» ${ }^{9}$. Este truco en una novela tradicional podría desecharse como un gastado esfuerzo de crear la ilusión de historicidad. El efecto de las notas y cartas en este caso es más radical. Primero, por lo que dice el transcriptor y por las contradicciones entre las cartas de los dos testigos de la muerte del reo, queda socavada la confiabilidad de Pascual como narrador, dudosa ya desde el principio por tratarse de una narración en primera persona. De este modo Pascual sufre otra condena, tal vez la peor, impuesta ahora por el propio texto. En segundo lugar, los documentos que circunscriben las memorias de Pascual convierten su narración en un texto dentro de un texto. El marco que la comenta envuelve el relato autobiográfico. El objecto escrito en sí, la palabra, sufre el destino de encerramiento. Además, el objeto escrito encerrado es un "yo" circunscrito por "ellos"; la narración en primera persona es la manifestación de una visión solipsista que separa al yo de las otras personas. Por fin, se recordará que el manuscrito de Pascual lo encontró el transcriptor en forma de un paquete bien atado con bramante. Salta a la vista este encierro literal de la literatura. No es posible subrayar de manera más eficaz la dialéctica entre libertad y cautiverio.

8. Según el esquema de Jorge Urrutia, "Introducción" a C.J. Cela, La familia de Pascual Duarte, Barcelona, Planeta, 1977, p. LXXXVI, la novela exhibe una estructura de dos momentos de reflexión y reposo (cap. 6-7, 13-14) encerrados por la violencia.

9. «Pascual en la cárcel: el encubierto relato de La familia de Pascual Duarte», Insula, N. 365,1977 , p. 5. Dougherty reconoce que el transcriptor es uno entre tantos personajes de la novela, uno entre los que desempeñan una obligación narrativa. Agnes Gullón, en su investigación de la posición autorial, no distingue entre transcriptor, autor y Cela ("La transcripción de La familia de Pascual Duarte», Insula, N. ${ }^{\circ} 377$, 1978, pp. 1, 10-11). 
La cárcel, a la vez que un castigo y una condena, es un santuario, un recinto protector, incluso una fuerza soteriológica. Coincidiendo con la tradición romántica que describe Brombert, la celda en la novela de Cela llega a ser el locus amoenus donde el reo piensa y sueña. La celda le inicia a Pascual en un movimiento centrípeto hacia el conocimiento del yo y es por lo tanto el mediador entre el hombre secuestrado y la adquisición de su conciencia personal, es decir, de su libertad. El texto subraya, repitiéndolo tres veces seguidas (p. 97), que los individuos que están libres viven sin fijarse en su libertad. Pascual reconoce la ironía de que el encerramiento le impulsa a expresar una vitalidad que no manifestaría si viviera tranquilamente y sin agonía (cap. ${ }^{\circ} 13$ ). Casi un siglo antes, Baudelaire ya había notado. este juego de perspectivas: "l'infini parait plus profond quand il est plus resseré» ${ }^{10}$. El marco o espacio restrictivo tiene una potencia amplificadora. Si no fuera por la celda, Pascual no tendría tal conciencia de lo exterior ni de sí mismo. De una interpretación de tal índole se desprende que la cárcel es un símbolo ambiguo. En efecto, esta visión se apodera de nosotros en el momento en que aceptamos la enseñanza cristiana de que el sufrimiento nos redime. El castigo y la separación resultan ser productivos, incluso en un mundo ya demasiado cínico y desesperado para buscar refugio en el sufrimiento.

Es productivo ese espacio/tiempo celular porque engendra la crónica de una vida. La celda es el catalizador del acto de escribir y de la aparición de Pascual como figura literaria. El encerramiento del individuo en la cárcel, en su mundo y en su propia constitución le incita a recogerse en su yo, y el escribir es la suprema manifestación del yo consciente de su trascendencia. La confesión escrita es el ápice del ensimismamiento; es la proclamación de una existencia vivida en soledad total y es la conversión de esta soledad en la única razón de ser del individuo. La noción moderna del solipismo creador se deriva de una amplia tradición que se extiende desde la celda monástica hasta el escritorio hermético de Proust. Señala Brombert: "Repressed freedom and poetic inventiveness are intimately related. This would explain the specific prestige of the sequestered artist. [...] The enclosed space is also the locus of artistic creativity» (p. 15). Y luego, refiriéndose a Stendhal, añade: "the most fundamental freedom is clearly associated with the act of writing. And his act belongs

10. Charles Baudelaire, "Salon de 1859", Oeuvres complètes, París, Gallimard, 1976, II, p. 653 . 
properly to the privileged world of claustration" (p. 87). Desde la celda que es su escenario particular, Pascual produce el drama artificial de su existencia. Digo produce, no reproduce, porque desde su perspectiva en el tiempo, Pascual crea su vida pasada. No es puro historiador e intérprete; es literalmente el inventor de sí mismo.

Las memorias como género literario son un acto de escribir cuyo sujeto es el yo. Cuando escribo mis memorias, me convierto en protagonista de mi propia creación literaria: un caso de disociación voluntaria. El yo que escribe y el yo materia de la escritura no son iguales. Sólo fingen o pretenden serlo. El uno es el yo creador; el otro es la proyección imaginativa de ese yo: es decir, creación, ilusión, ficción. Como dice Artemio Cruz en la novela de Carlos Fuentes, «la memoria es el deseo satisfecho». El escrito autobiográfico supone un proceso de selección y supresión de la materia disponible, tal como ocurre en la creación ficticia. En vez de sospechar que una confesión es una máscara, se puede confirmar el hecho; y en vez de censurarlo, se puede aplaudirlo, pues la máscara inventada adquiere una trascendencia de que la persona que escribe está desprovista -aunque la va ganando, precisamente porque escribe. El propio Pascual comunica esta idea de un yo escindido que compone las memorias: «al contarlo tan alejado me encuentr[o] de todo lo pasado como si lo contase de oídas y de algún desconocido" (p. 146). El viaje de Pascual hacia sus orígenes le descubre una identidad nada agradable que con el instrumento de la escritura se esfuerza por suavizar. En la "Carta anunciando el envío del original", ya hace presente la doble limitación de las memorias frente a la verdad histórica: la falibilidad de la memoria y el proceso de selección: "es por lo que me he inclinado a relatar algo de lo que me acuerdo de mi vida" (p. 51; el subrayado es mío); y sigue: "parte hubo que al intentar contarla sentía tan grandes arcadas en el alma que preferí callármela y ahora olvidarla" (p. 52) ${ }^{11}$. Paul Ilie señala acertadamente (p. 47) que la respuesta razonada en Pascual surge tardíamente en la cárcel y que, por consiguiente, su versión de su vida es una formulación posterior que suprime ciertos datos. Cuando Pascual dice que suelta sus ideas como le salen y no se para a "construirlo como una novela", al lector no se le escapa la ironía de que sí se trata de un relato novelesco.

11. Más tarde añade: «De aquel tiempo guardo un recuerdo confuso y vago y no sé hasta qué punto relataré fielmente lo sucedido; voy a intentarlo, sin embargo, pensando que si bien mi relato pueda pecar de impreciso, siempre estará más cerca de la realidad que las figuraciones que, de imaginación y a ojo de buen cubero, pudiera usted hacerse» (p. 71). 
Pero la sensación de una presencia escrita, inventada, aunque la sustente la tinta en vez de la sangre, aumenta la impresión de que un ser humano palpable ocupa estas páginas. Con las 359 cuartillas que llena, Pascual pasa por un camino de auto-realización que empieza con la purgación. Al mismo tiempo que Pascual se encuentra en la cárcel, el encarcelamiento se sitúa dentro de él; es decir, le encierran por ser culpable, pero también es prisionero de su sentimiento de culpabilidad. Con el documento que compone se redime, y al convertir lo ocurrido en palabra, se siente aliviado, según su propia confesión: "como del aplanamiento en que me hundo no de otra manera me es posible salir si no es emborronando papel y más papel, voy a ver de empezar de nuevo, de coger otra vez el hilo del relato» (p. 144; vid. también p. 53). El proceso de purgación pasa por las etapas tradicionales de encerramiento y escritura.

El acto de escribir es una ablución espiritual para Pascual. Así lo reconoce Urrutia: «La escritura de las memorias alcanza, para su autor, la función de autocomprensión, autocastigo y tranquilidad» (p. I.XIV). También Spires ha entendido que el Pascual contemplativo "se descubre a sí mismo contando sus desventuras como protagonista” (p. 45). Pero la empresa de contar desempeña más que una función iluminadora y purgativa para el relator, pues escribiendo Pascual se afirma y se inmortaliza. $Y$ de este modo gana su libertad, porque al escribir crea a un nuevo personaje que, sin dejar de ser él mismo, es una nueva persona. Si la apertura es mental y figurativa más bien que física y literal, no es por eso menos importante.

Dougherty en su artículo dice con acierto: "He aquí, pues, el relato encubierto de la novela: al escribir sus memorias, Pascual renace y experimenta en su presente carcelario una libertad que desea perpetuar" (p. 5). Pero aunque reconoce que la confesión de Pascual es literaria más que religiosa, Dougherty pone más énfasis en el resultado ontológico que en el proceso creador. Pascual se escapa de sus limitaciones no sólo porque llega a ser otro hombre, sino porque hace frente al mundo con un acto - uno de los pocos en su vida, quizás el único- que responde a su propia voluntad: reemplaza la realidad de su existencia con una creación artificial suya. Desde la dedicatoria a don Jesús, donde se refiere a sí mismo como «el autor de este escrito", Pascual está consciente de que su capacidad de trascender su mortalidad restringida reside en su condición de escritor. Hace constar sin lugar a dudas que al escribir se define y se certifica, y cuando piensa en la posibilidad de que los acontecimientos puedan impedir 
que termine sus memorias, le entra el pánico. Puesto que las páginas de Pascual son las confesiones de un condenado al patíbulo, la trayectoria de lo escrito -el contenido del relato- conduce a Pascual a la muerte, mientras que la trayectoria del acto de escribir-el hecho escrito- le lleva a la vida, a la vida eterna.

Cela termina así su introducción a la edición definitiva de su novela: «En fin: Pascual Duarte está de limpio, que es lo importante. Ahora se dispone a empezar a morir de nuevo, poco a pocom ${ }^{12}$. Por cierto, Pascual es escritor y escritura. Como autor de sus memorias no nos convence necesariamente cuando dice que de veras no es malo: pero como protagonista de sus memorias se proyecta más allá del hombre que es. En términos platónicos, el cuerpo, como la Cueva, encierra el alma en un estado de error y ceguera espiritual. Las memorias de Pascual son su esfuerzo de liberarse de este encadenamiento. El cuerpo - el hombre mortal- no escapa ni de la prisión ni de la muerte. Bien sabemos que la muerte de Pascual no es su liberación. Pero el hombre ajusticiado que reposa para siempre encerrado en su tumba adquiere plena vida siempre que un lector le resucite, y por eso sigue viviendo. Un estudioso del tema ha dicho recientemente que el deseo de inmortalidad siempre es el movil del escrito autobiográfico $^{13}$. Su fin es no tener fin. La primera frase de la «Nota del transcriptor» ya anuncia esta apertura a través de lo escrito: «Me parece que ha llegado la ocasión de dar a la imprenta las memorias de Pascual Duarte" (p. 49). Estas memorias son una clara indicación de que el aislamiento del individuo, sea literal o figurativo, aumenta su necesidad de comunicación. El yo secuestrado anhela proyectarse. $Y$ con la palabra cumple Pascual este proyecto, pues si a él no le es permitido escaparse de su confinamiento, su texto sí descubre las puertas abiertas. De la prisión pasa el manuscrito al cajón de un escritorio y de allí a una farmacia. Luego se desembala el paquete que contiene las hojas del manuscrito; y de igual modo se desenreda el texto cuando el lector abre el libro que, abriéndose, deja manifiesta una existencia. El ente de ficción no tiene que sufrir el castigo de lo infinito, y así el prisionero condenado queda liberado. Existe un texto de Pascual y existe Pascual como texto.

12. "Pascual Duarte, de limpio», Obra completa, I, p. 46.

13. Jeffrey Mehlman, A Structural Study of Autobiography, Ithaca, N.Y., Cornell University Press, 1974. 
Una de las dimensiones más importantes de esta obra de Cela es su autorreflexividad como objeto escrito. Aquí se encuentran toda una serie de escritores -Pascual, el transcriptor, don Joaquín Barrera López, el cura don Santiago Lurueña, el guardia don Cesáreo Martín- a través de los cuales se manifiestan el goce, el dolor y la necesidad de escribir. El hecho de que Pascual produzca un texto que le convierte en texto es tan importante como el texto que produce, porque si Pascual es escritura y existe como texto, queda confirmado el poder de la palabra. Al tomar la pluma, Pascual emprende la reconstitución del pasado y realiza un proceso iluminador que le lanza a la conciencia de sí mismo. Si no se hubiera puesto a escribir, no habría adquirido forma su existencia. Dice: "me espanta pensar con qué puntualidad me es fiel la memoria, en estos momentos en que todos los hechos de mi vida [...] van quedando escritos en estos papeles» (p. 96). Pero el tiempo es el enemigo de la palabra, y el propio Pascual reconoce que el presente escrito no puede cambiar de veras el pasado vivido. Por eso recurre a la solución de trastocar su historia en discurso y de convertirse él mismo en memoria: es decir, en palabra escrita que tiene vida duradera en la memoria de otros por ser vida en el presente del lector.

El defecto trágico de Pascual a lo largo de su vida es su visión limitada que no columbra otra solución que la violencia ante los problemas que se le presentan. No sabe resolver sus dilemas de otro modo porque no tiene el don de la palabra. En su primer encuentro con el Estirao se muestra lamentablemente incapaz de articular sus sentimientos, como él reconoce: "A mí me ganaba por la palabra, pero si hubiéramos acabado por llegar a las manos le juro a usted por mis muertos que lo mataba antes de que me tocase un pelo" (pp. 79-80). ¡Cuánto se equivoca en ese momento al añadir: "fue la única pelea que perdí por no irme a mi terreno» (p. 81)! Todavía no ha llegado a ser su terreno la palabra cuando, testigo de una disputa de honor entre dos hombres en el Retiro de Madrid, no entiende por qué ellos mantienen la contienda en un nivel verbal. Pero al final de su vida en la cárcel, ya ha aprendido el poder de la palabra y recurre a la verbalización como solución existencial. Cuando Pascual dice: "Quizás encuentre usted presumido este afán mío de que las cosas secundarias me salgan bien cuando las principales tan mal andan" (p. 145), deja entrever que la experiencia vivida y la amenaza de muerte en este momento le importan menos que sus memorias. La escritura, que por su carácter pretérito suele andar en pos de la vida, ya ha ad- 
quirido la primacía por encima de la vida. La sensación liberadora que experimenta Pascual no surge del mero proceso de revivir el pasado, como sugiere Spires (p. 49); se trata de una recreación lingüística, un revivir a través de la palabra, por lo cual no es la doble perspectiva temporal sino la fuerza del lenguaje escrito lo que consuma la liberación. La descripción de la experiencia es más poderosa que la experiencia.

Paul Ilie, al comentar el primitivismo de Pascual, contrasta su actuación directa con el comportamiento más refinado y simbólico del hombre social: "Todos los organismos son seres sintientes, pero pocos pueden coordinar sus impresiones en una formulación independiente exterior a sí mismos. Los que lo hacen, someten a un auténtico exorcismo a sus emociones, y de ahí su imperturbabilidad. Pascual está constantemente "sintiendo", pero vive en el hermetismo de un reducto psíquico que no admite salida. Tiene todavía que llegar al estadio de plena acción simbólica" (p. 56). Al decir esto, Ilie prescinde de Pascual escritor, pues la reflexión y la recreación por escrito convierten lo sentido y lo experimentado en simbólico. Las cuartillas que llena Pascual son por cierto «una formulación independiente exterior a sí mismom. El propio transcriptor, en su nota final, pone en duda el supuesto carácter olvidadizo de Pascual y sugiere que era capaz de preparar su manuscrito "con todo cálculo para que surtiese su efecto a su tiempo debido» (p. 196). Ilie reconoce luego (pp. 62-63) que para plasmar su remembranza, Pascual necesita de la razón y de la suficiente distancia y reserva para dar explicaciones. Toda la teoría del primitivismo que esboza con tanta perspicacia Ilie concuerda con el carácter del Pascual que vive en el pasado de las memorias, pero se derrumba ante el Pascual que escribe en el presente en su celda. Este Pascual ya maduro e iluminado ha conquistado las abstracciones de la palabra y sabe prescindir de toda comunicación que no sea lingüística ${ }^{14}$. Pascual llega a esa categoría que Ilie le atribuye al hombre civilizado: «El hombre civilizado es lo bastante contenido o

14. Algunos le han reprochado a Cela el desacuerdo entre el estilo metafórico de su novela y el rudo origen de su narrador; por ejemplo, Ilie, p. 38; Juan L. Alborg, Hora actual de la novela española, I, Madrid, Taurus, 1958, p. 79 ss. Se han despistado estos críticos por su insistencia en un proceso mimético cuya meta es la verosimilitud a pesar de que tales presiones de fidelidad ilusionista no le han guiado a Cela. La riqueza con que se expresa este campesino es una medida de su condición de escritura que trasciende su origen extremeño. Del mismo modo, lo que escribe, en cuanto expresión metafórica, arte duradero de la palabra, sobrepasa las presiones limitadoras del espejismo psicológico y circunstancial. 
refinado para hallar satisfacción por el medio sutil de las palabras" (p. 65). El Pascual que no sabe más que el lenguaje de la violencia es creación del Pascual en pleno dominio del lenguaje del hombre social.

Si al lector se le escapa lo poco fiable que es Pascual como narrador, el desliz se debe a la triple constitución lingüística de Pascual que le dota de una fuerza extraordinaria: 1) como personaje ficticio es por constitución palabra; 2) como persona nacida de una ilusión se désarrolla para apoderarse al fin del arma de la palabra; y 3) como autor de sus memorias es responsable de su reconversión definitiva en palabra. La locución que escoge el transcriptor para dar aviso del asesinato del Conde don Jesús hace hincapié en la condición simultánea de Pascual como creación y creador: "del que nuestro personaje fue autor convicto y confeso" (p. 196; el subrayado es mío). La literatura, según Jean-Paul Sartre, es un proyecto en busca de un sentido (Qu'est-ce que la littérature?, cap. ${ }^{\circ}$ 2). Literalmente proyecta en un futuro un significado que no existía antes. Páscual al convertirse en literatura proyecta en el futuro de su lector un significado de que carecía en su pasado. Como todo autor de memorias, Pascual está a la misma vez fuera y dentro de su texto. En su función de autor-creador, está libre y tiene el poder de moldear su propia figura según la concibe. Como personaje-creación, es prisionero de su texto, definido para siempre. Este encerramiento en un texto, como texto, es precisamente lo que quiere conseguir; pero el autor de este texto lo quiere ser él, porque sólo él puede trocar un pasado pecaminoso en una presencia humana suscitadora de entendimiento y compasión. Esta escisión del yo que consigue Pascual escribiendo sus memorias la anhelaba ya antes en su vida cuando, impulsado por su yo, quería ser otro. "Quería poner tierra entre mi sombra y yo, entre mi nombre y mi recuerdo y yo, entre mis mismos cueros y mí mismo, este mí mismo del que, de quitarle la sombra y el recuerdo, los nombres y los cueros, tan poco quedaría" (p. 187). En aquel entonces, poco antes del asesinato de su madre, no era capaz de conseguir esa liberación de sí mismo. Ahora ha descubierto que, en efecto, puede «borrarse como un muerto" y transformarse en ángel. Y para los ángeles no hay prisión.

Desde su celda, en un momento de reflexión, Pascual describe la perspectiva hacia afuera que se le presenta:

El sitio donde me trajeron es mejor; por la ventana se ve un jardincillo, cuidadoso y lamido como una salita, y más allá del jardincillo, hasta la serranía, se extiende la llanada [...]. 
Yo veo la mariposa toda de colores que revolea torpe sobre los girasoles, que entran por la celda, da dos vueltas y sale, porque con ella no va nada, y que acabará posándose tal vez sobre la almohada del director.

...Yo cojo con la gorra el ratón que comía lo que yo ya dejara, lo miro, lo dejo - porque con él no va nada-y veo cómo escapa con su pasito suave a guarecerse en su agujero, ese agujero desde el que sale para comer el rancho del forastero, del que está tan sólo una temporada en la celda de la que ha de salir para el infierno las más de las veces...

Uno puede apreciar muy fácilmente que la bonita mariposa representa la libertad de que carece Pascual, mientras que el ratón en el agujero de la celda de la prisión es el apto compañero de su confinamiento. Extendiendo la metáfora, es posible imaginar en el vuelo de la mariposa los arranques de la imaginación, el arte, la belleza; y en el ratón la visión gris de la sordidez y sinuosidad de la sociedad contemporánea. Puede ser...

Pero a fin de cuentas, no es la mariposa la que simboliza la solución ante el dilema de la existencia. La solución se vislumbra tanto en el ratón como en la mariposa. La misma creación de las dos criaturas y su coexistencia en yuxtaposición metafórica en un acto de fe de parte del artista. En un contexto novelístico, el ratón y la mariposa son iguales en su constitución y función de lenguaje. Si el escritor no puede escaparse de su sentimiento de encierro y enajenación, entonces la proyección imaginativa de ese sentimiento a través de la palabra es una solución, tal vez la mejor solución. Si la separación voluntaria o impuesta es una señal de alineación, el acto de escribir es la expresión de la conquista de la alienación. Llámese Cela o Pascual Duarte, mientras que escribe el escritor, queda abierto el camino, porque queda un texto que leer. 